\title{
Introduction to the Smart Service Systems with Analytics \& Open Tech Artificial Intelligence
}

\author{
Haluk Demirkan \\ U. of Washington-Tacoma \\ haluk@uw.edu
}

\author{
James C. Spohrer \\ IBM Almaden Research Center \\ spohrer@us.ibm.com
}

\author{
Ralph Badinelli \\ Virginia Tech \\ ralphb@vt.edu
}

Human centered smart service systems (smart services, smart devices etc.) can be characterized by: (1) the types of offerings to their clients, (2) the types of jobs or roles for people within them, (3) the types of returns they offer investors interested in growth and development, through improved use of technology, talent, or organizational and governance forms, which create (dis)incentives that (re)shape behaviors, and (4) the personalization of the co-creation of value. An important trend in smart service systems is the increasing availability of cognitive assistants (e.g., Siri, Watson, Echo, Cortana) to boost productivity and creativity of all actors. Innovators of smart service systems, including entrepreneurs, managers, policymakers seek to improve quality-of-service for customers, quality-oflife for citizens, and/or quality-of-returns for investors.

Smart service systems are ones that continuously improve (e.g., productivity, quality, compliance, sustainability, etc.) and co-evolve with all sectors (e.g., government, healthcare, education, finance, retail and hospitality, communication, energy, utilities, transportation, etc.). Regional service systems include nations, states, cities, universities, and hospitals. Global service systems include multi-national businesses, professional associations, and NGOs. Natural or human-made disasters, technology failures, criminal activities, political collapse can disrupt or negatively impact quality-oflife for people living and working in service systems.

In part because of technology platforms, smart service systems often exhibit increasing levels of customer co-creation of value. Global social media platforms, like Facebook, Twitter, and LinkedIn, are exemplars of service systems organized as business entities that exhibit customer co-creation of value through content sharing. Even manufacturers and agricultural businesses offer upstream and downstream service offerings to their customers, and can exhibit customer co-creation of value. The rise of "localvores" supports local sustainable production of food and other renewable resources. Spohrer et al. [2007] ${ }^{1}$ define a service as the application of competence and knowledge (e.g., technology, organizational forms, business models, etc.) to create value between providers and receivers

${ }^{1}$ Spohrer, J., Maglio, P. P., Bailey, J., and Gruhl, D. Steps toward a science of service systems. IEEE Computer, 40, 1 (January 2007), 71-78.

URI: https://hdl.handle.net/10125/63946

978-0-9981331-3-3

(CC BY-NC-ND 4.0) for mutual benefits. The overall goal of service science is to provide a foundation to advance our ability to design, improve and scale service systems for practical business and societal purposes (Demirkan et al. [2009] $^{2}$. In 2013, the National Science Foundation also recognized the need for research and initiated a new program called "NSF Industry and Academe: Enabling Smart Service Systems

Using big data analytics and cognitive systems to improve decision-making, service providers try to compete for the hearts, minds, and wallets of collaborators by (1) improving existing offerings, (2) innovating new types of offerings, (3) evolving their portfolio of offerings, and, (4) changing their relationships to others in the ecosystem in ways stakeholders perceive as more positive, sustainable, fair, or responsible.

The goal of this track is to explore the challenges, issues and opportunities related to innovation of smart service systems that enable value co-creation with analytics, artificial intelligence and people. This is the sixth time that we are offering this minitrack since 2015. One paper has been accepted for the Minitrack to investigate these issues in different ways.

The, titled "Smart Service Systems in Manufacturing: An Investigation of Theory and Practice" by Markus Heuchert, Yannick Verhoeven, Ann-Kristin Cordes and Jörg Becker investigated smart service systems in the domain of manufacturing. They followed a multi-method approach by doing a comprehensive literature analysis that is being combined with in-depth expert interviews. Five barriers of adoption were identified and further discussed regarding the implications for research. These barriers are economical, technological, know-how, the lack of trust and regulations. As their research shows, the proliferation of smart services includes technological progress and the composition of the market and its actors.

We hope you enjoy the papers and their presentation at the conference. We thank the authors for submitting their work to make this another engaging minitrack. We also thank the reviewers for their valuable feedback.

\footnotetext{
${ }^{2}$ Demirkan, H., Kauffman, R.J., Vayghan, J.A., Fill, H-G., Karagiannis, D. and Maglio, P.P., (2009) "Service-Oriented Technology and Management: Perspectives on Research and Practice for the Coming Decade,” The Electron-
} ic Commerce Research and Applications Journal, 7 (4), 356-376, Jan. 